\title{
Disadvantaged neighbourhoods and young people Not in Education, Employment or Training at the ages of 18-19 in England.
}

\author{
Journal of Education and Work
}

Magdalene Karyda

Department of Social Science, University College London Institute of Education WC1H OAL, London, UK

Tel: +44(0)7792245090

mkaryda@gmail.com (corresponding author)

Orcid public record: http://orcid.org/0000-0002-2966-8974

\author{
Andrew Jenkins \\ Department of Social Science \\ University College London Institute of Education \\ WC1H OAL, London, UK \\ Tel: $+44(0) 2076126898$ \\ andrew.jenkins@ucl.ac.uk
}

To link to this article: https://doi.org/10.1080/13639080.2018.1475725 


\section{Disadvantaged neighbourhoods and young people Not in Education, Employment or Training at the ages of 18-19 in England.}

There is a growing interest among researchers in the impact of locality on young people who are inactive and not engaged in education, employment or training (NEETs). Previous research on this, however, is rather limited and does not account for a number of characteristics that mediate the effects of disadvantaged neighbourhoods on transition outcomes. This study investigates the effects of neighbourhood context on young people who experience NEET status at the ages 18 to 19 in one cohort born in 1989/90 in the Longitudinal Study of Young People in England - LSYPE. The analyses control for a wide range of factors which may affect NEET status. Drawing on previous sociological theories, we develop a theoretical framework that specifies four levels of influence on young people's development: individual, family, school and peer group characteristics. Potential pathways between neighbourhood context and individual outcomes are explored using a logistic regression model. We demonstrate that there is a higher probability for young people who live in high crime areas to become NEETs in comparison to those who live in less-deprived areas.

Keywords: NEET, education, youth unemployment, neighbourhoods, area deprivation

\section{Introduction}

Research in young people's trajectories after compulsory education suggests that spending time disengaged from education, the labour market and training can have serious and lasting consequences both for young people and for the society as a whole. Those who leave full time education early tend not to return to it (Dickerson and Jones 2004) and are therefore likely to have lower educational attainment as a result. One study found that young people who had been NEET remained disadvantaged in their level of educational attainment a decade later. More than one in five of NEET young people in 2001 had no qualifications in 2011, compared with only one in twenty five of 
non-NEETS (Feng, Everington, and Ralston 2015). This in turn means that they will be more likely to be out of work later on in their career and to have lower earnings (Bell and Blanchflower 2011, Gregg and Tominey 2005, Mroz and Savage 2006). The experience of being NEET was also associated with poorer physical and mental health in adulthood (Oreopoulos and Salvanes 2011). As well as the impact on the individuals themselves there are also adverse effects for the society because NEETs are more likely to be benefit claimants and the lower earnings of former NEETs leads to reductions in tax revenue for the Exchequer. One estimate for the UK economy put the costs of NEET at $£ 12$ billion in 2008 prices, mainly due to increased benefit payments and lost tax revenues, but also some additional costs for the health and criminal justice systems (Coles et al. 2010).

Even though young people in NEET status have been extensively studied in recent years (Bynner, Ferri, and Shepherd 1997, Furlong 2006, Maguire 2015), there has been very little research on the association between neighbourhood poverty and young people's trajectories. Evidence suggests that the population of NEETs tend to be concentrated in particular towns and cities (Crowley and Cominetti 2014) and that many young people who are NEET may have spent much of their childhood living in disadvantaged areas (Thompson, Russell, and Simmons 2014). Existing evidence is, however, rather limited in that no study has used a large and nationally representative sample while little attention has been given in uncovering empirically the mechanisms that connect neighbourhood context to individual educational and employment outcomes.

Understanding the role of neighbourhoods on young people's outcomes has been an enduring sociological question. Classic sociological theories have focused on poor neighbourhoods and represented them as important social spaces for their residents 
(Murray 1999, Wilson 2012). One domain in which these classics have in particular focused was the importance of social disorganisation and criminal activity and the influence it had on its residents. This study draws upon the arguments of classic sociological theories to explain the effect of living in a disadvantaged neighbourhood with high crime on young people's decisions after compulsory education.

Neighbourhood effects research has been hampered by two problems. The first problem relates to the difficulty to conceptualise neighbourhoods and define their boundaries in order to capture both structural and social characteristics (Galster 2008, Lupton 2003). The second involves the selection bias issue; it has been difficult to include in the analysis all the factors that affect both neighbourhood of residence and individual outcomes that could potentially account for the association between area deprivation and young people's outcomes (Hedman and van Ham 2012). This study extends research on neighbourhood context by (a) exploring the association between area deprivation and young people's trajectories, (b) using a measure of multiple deprivation (the Indices of Multiple Deprivation) that define neighbourhoods at the level of small localised neighbourhoods and allow both structural and social dimensions to be captured, and (c) using rich, individual-level longitudinal data for England to control for a wide range of factors which may affect both the selection of neighbourhood of residence and NEET status.

The remainder of this paper is organised as follows: the next section reviews previous literature and theoretical background on the ways in which neighbourhood characteristics could influence educational and employment outcomes of young people including NEET status; subsequent sections outline the data source and methods used and present the results. A final section discusses the implications of the findings. 


\section{The NEET group}

There has been considerable debate about the best way to describe those people who are neither engaged in education nor in paid work. In the 1990s inactive young people, neither in education nor in training or employment, were described in career service records using the terms "status zero" (Williamson 1997), "getting nowhere", and "zero register" (Bynner, Ferri, and Shepherd 1997). The term NEET was initially used to describe 16 and 17 year olds who were no longer eligible for unemployment benefit due to legislative changes (Maguire 2015). Since then, the scope of the term has broadened to encompass a wider group of young people. The broad NEET concept ignited academic debate due to its heterogeneous composition of groups with different characteristics. The NEET classification comprises individuals from a variety of backgrounds (Furlong 2006). NEET experience can be short or prolonged in duration, or repeated (Raffe 2003). Some young people move in and out of employment and education, whereas others remain detached both from education and the labour market. NEETs can be engaged in different activities including parenthood, illness, caring for others, or searching for education and training. The NEET categorization also excludes a group of young people who are employed in precarious jobs and would benefit from policy interventions (Roberts 2011).

Insights on the barriers to employment and education for young people have come from both qualitative and quantitative approaches. Qualitative research has focused on different narratives, experiences of transitions and the interpretation of these experiences. Various NEET status narratives have been presented to depict different experiences. These narratives relate to the concepts of vocational status, selfactualisation, meaningful activity, convenience, money, leisure and life problems (Reiter and Schlimbach 2015). Experiences of fractured transitions were associated with 
repeated exclusion from school before the age of 16 (Finlay et al. 2010). NEET status has been described as an undesirable experience where young people lose their sense of identity and become distant from the contexts of education, training and work (Thompson, Russell, and Simmons 2014). Young people interpreted the experience of NEET as a result of racism, ethnic marginalisation and class disadvantage which, for a limited number of them, became the source of inspiration to overcome barriers and pursue future goals (Devadason 2006).

Quantitative analyses have focused on the influence of parental characteristics, family practices, educational attainment, attitudes to school and peer group influence. Parental characteristics such as parental socio-economic status, parental educational attainment, mother's age at birth of the young person and whether young people live in single parent families have all been found to influence young people's trajectories (Britton et al. 2011, Wolf 2011). Parental practices, for example low interest and involvement in a young person's schooling, negative attitudes towards education and low aspirations have been associated with young peoples' decisions not to continue to higher education (Rennison et al. 2006). Individual characteristics of young people that constitute the most important barriers are poor educational attainment and low levels of qualifications (Bell and Blanchflower 2010, Bynner and Parsons 2001, Strand 2007). High levels of truancy and not enjoying schooling constitute attitudes that are found to maximize the likelihood of leaving school (MacMillan, Gregg, and Britton 2012). Finally, peer group exclusion and participation in antisocial and / or criminal activities can have a negative influence on students' academic performance (Larsen, Jensen, and Jensen 2014) and create a barrier to smooth transitions from education to work (Spielhofer 2009). 


\section{Theoretical perspectives on the impact of living in deprived neighbourhoods}

The consequences of living in disadvantaged neighbourhoods are a central dimension of ecological models and sociological theories of neighbourhood effects. In the ecological framework, the Life Course theory (Elder 1998, Giele and Elder 1998) and the Ecological Systems theory (Bronfenbrenner 1979) have examined proximal and distal influences on individual development. The Life Course theory has been an interdisciplinary approach that proposes a research framework to study the timing of lives, linked or interdependent lives, and human agency in making choices. The Ecological Systems Theory of Bronfenbrenner (1979), developed further by Garbarino (1982) and Steinberg (1990) has also been influential in understanding young people’ trajectories. The key focus of these views is on individual development in context, taking into consideration the impact of multiple levels of influence. Bronfenbrenner (1979) suggested that young people's development is the result of the interaction between the quality and context of the environment and the young person. The context of an individual's environment is multi-dimensional, extending from the immediate family environment to the wider community and the social and historical context. Parental characteristics, neighbourhood characteristics, socio-historical conditions and individual ability interact to explain the directions that young people follow in life. Developmental processes act in the proximal and the distal environment experienced by the individual. The proximal environment is the basic context for development and refers, for example, to the family environment which offers daily contact and experiences. Distal cultural and social values have an indirect effect on the individual and are often mediated by the proximal environment.

Sociological theories of neighbourhood effects focus more on the distal influences on individual development and can be broadly grouped into three categories: 
social organization, social isolation and neighbourhood resource theories. Social organization theories of neighbourhood effects emphasize the importance of social cohesion, regulation of crime and monitoring of youth behaviour (Sampson, Morenoff, and Gannon-Rowley 2002). Building on the classic study, "Juvenile Delinquency and Urban Areas" by Shaw and McKay (1942) this approach suggests that high crime and delinquency rates are explained by low economic status of the area, ethnic heterogeneity that increases fear and reduces social cohesion, and residential mobility that disrupts community networks and social relations. Criminal acts are reinforced, especially among young people who participate in anti-social behaviour. Residents do not share a set of common values, communication is disrupted, the community is not controlled or policed by outside agencies and unrestricted freedom of individuals results in delinquent behaviour. These communities are also characterized by lack of collective efficacy (Sampson 1997) which refers to lack of social cohesion, unwillingness to improve residential areas, and inability to control and regulate members of the community (Sampson 2001). Similarly, the underclass theory (Murray 1999, Wilson 2012) describes deprived neighbourhoods as contexts that are linked to social stratification, criminality, and withdrawal from the labour force among young males. Lack of collective supervision may increase young people's engagement with antisocial behaviour (Barry and Garbarino 2001) and influence educational attainment negatively (Browning, Leventhal, and Brooks-Gunn 2005).

Social isolation theories refer to deprivation in terms of a lack of social connectedness. Here residents of poor neighbourhoods are isolated from social networks and institutions which could provide them with information about job opportunities, while adults in deprived areas fail to provide role models that could promote young people's participation in education, training and employment. Notable 
proponents of social isolation theories include Jencks and Mayer (1990), whose epidemic model of neighbourhood effects points to the behaviour of peers and neighbours that spreads to residents and young people in a community. The concept of social capital (Coleman 1988) is also very relevant to this discussion. Croll (2004) places emphasis on social ties developed in families, schools and neighbourhoods which help transfer community values and can promote or hinder cognitive development and employment outcomes for young people. Furthermore, the epidemic hypothesis (Case and Katz 1991, Crane 1991) is a framework that suggests that concentrated poverty and deprivation of social networks in disadvantaged neighbourhoods increase the likelihood that young people will be exposed to antisocial behaviour and violence through regular interaction with their peer group. It is more likely for young people living in socially deprived areas to engage in criminal activities if crime is prevalent in their area of residence and they lack access to the social networks that would permit them to get positive influence from mainstream behaviours and attitudes. The prevailing culture in disadvantaged areas may also undervalue the importance of formal schooling and assign value to risky behaviours (Anderson 2000).

Finally, neighbourhood resource theories focus on the availability of institutional resources which can promote academic achievement and therefore increase employment opportunities (Jencks and Mayer 1990, Leventhal and Brooks-Gunn 2000). Such resources include libraries, good-quality schools, day-care services and recreational areas which young people and their parents can take advantage of and which can help improve academic achievement (Small and Newman 2001). School quality is a key mechanism that links neighbourhood characteristics and young people's educational and developmental outcomes. From this perspective neighbourhood deprivation undermines effective parenting due to the scarcity of amenities, poorer 
public schools and a more transient population, all of which can be disruptive to young people's development (Maholmes and King 2012).

Both the ecological and sociological approaches emphasize that neighbourhood effects can be direct on their residents or indirect acting through proximal levels of influence. The degree of proximal or distal neighbourhood effects is likely to depend on the development period of young people (Aber et al. 1997). In the pre-school years children spend their time at home with their parents or in nursery schools. The effect of the neighbourhood is hypothesised to be indirect occurring mainly through influence on the home environment or in the caring facilities offered locally. While at first glance this effect might not seem important, previous research has found that the level of deprivation in electoral wards has a significant association with low test scores in preschool years even after controlling for family socio-economic characteristics (McCulloch and Joshi 2001). During their school years children spend less time at home than when infants and more time at school and with their peers. The quality of interactions with teachers and students influences development during childhood. During early adolescence, young people change both biologically and psychologically; they become more autonomous, and develop a sense of personal identity. During this period, young people come closer to peer groups, get involved with school and leisure activities and with formal and informal organisations in their neighbourhood (Aber et al. 1997). As young people become more involved locally, neighbourhood effects are regarded as increasing in scale. Late adolescence and early youth signify preparation for work and independent family life and pre-suppose higher contact with neighbourhood institutions such as, for example, networks for employment opportunities.

Drawing on the assumptions formulated by the ecological systems theory, social organisation theories, and social isolation theories we put forward the "compositional 
model of neighbourhood effects" (Karyda 2015). We stand on the arguments of these classic sociological theories and adapt them, in our effort to understand the experiences of young people and to explain a contemporary problem. Young people's development is informed by the framework of the multiple spheres of influence of the ecological systems theory. Arguments about how disorganisation distinguishes poor neighbourhoods from others, are drawn by social organisation theories that focus on violence and crime in the area of residence. Assumptions about social context are drawn by social isolation theories that connect social characteristics of neighbourhoods and young people's behaviour. Our model introduces four pathways that link neighbourhood deprivation to young people's behaviour: a) family characteristics, parental practices and aspirations, b) individual characteristics and educational attainment, c) peer group influence and antisocial behaviour, d) school experience, attitudes to schooling and young person's perception of educational attainment. The first two pathways refer to the structural characteristics of individuals who live in disadvantaged areas. The last two pathways address the influence of social context on young people.

\section{Data}

This study uses data from the Longitudinal Study of Young People in England (LSYPE), also known as 'Next Steps'. The main aim of the LSYPE is to provide information about the transitions young people make from the teenage years through to early adulthood including entry and exit from secondary and tertiary education, training and the labour market. Over 15,000 young people were first interviewed for the survey in 2004 (Wave 1) when they were aged 13. Interviews then took place on an annual basis until respondents had reached the age of 19 (Wave 7). Parents or guardians were also interviewed in the first four waves to provide a full picture of the young people's households. The design of the LSYPE involved over-sampling of those from deprived 
backgrounds and ethnic minority groups. There was also, unsurprisingly, some attrition from the sample over time such that just under 10,000 young people were still participating by Wave 7 . We use a set of longitudinal weights, supplied with the dataset, to address these issues.

Defining neighbourhoods is a complicated issue because neighbourhoods are not only physical but also social spaces (Lupton 2003, Massey 1994). Because the data available do not provide compatible spatial and social boundaries, researchers have sought to construct measures to address these issues. One of the most widely used approaches has been the Indices of Multiple Deprivation (IMDs) (Unit 2004) which are built through seven indices at the small area level and are suitable to capture social, economic and physical characteristics and to measure multiple deprivation. The IMDs, however, cannot be used to compare neighbourhoods and cannot measure neighbourhood change over time. Another approach has been the Unadjusted Meanstested Benefit Rate (UMBR) that is based on the ratio of claimants of means tested benefits to the number of households in a small area (Fenton 2013). The UMBR allows spatial changes in poverty to be measured, however, because it comprises a single component, the UMBR is not a measure of multiple deprivation but rather a measure of poverty.

This study employs the IMDs as a measure of neighbourhood geography which allows both structural and social aspects of neighbourhoods to be identified at the lower Layer Super Output Area (LSOA) level. Each LSOA is a small area of around 1,500 people with consistent geographic boundaries. In addition, LSOAs reflect social aspects of neighbourhoods, since they attempt to delineate areas with similar social characteristics. The LSYPE was linked to the seven decomposed Indices of Multiple Deprivation for the purposes of research into the impact of neighbourhood 
characteristics. Of the seven indices of multiple deprivation, the current study focuses on the crime deprivation index.

Data on area deprivation, family socio-economic status, parental practices, individual characteristics, attitudes to school and peer group characteristics was collected when the young person was 13 (Wave 1) and linked to information about the experience of not being in education, employment or training at the ages of 18 to 19 (Wave 7). Young people who moved to a different neighbourhood after the age of 13 were removed from the sample. The Crime Score Index of area deprivation was reversed, standardised and coded into quartiles with the highest quartile (coded 4) signifying the most deprived areas and 1 being the least deprived areas. Information about the examination results (Key Stage 2) of those young people in the survey is taken from the National Pupil Database (NPD) which has been linked to the LSYPE. Key Stage 2 attainment results were used in the analysis after being standardised and split in quartiles. The definition of NEET is taken as referring to those who had six months or more not in education, employment, or training as measured for two consecutive years, at the ages 18 to 19 . About 15 per cent of the sample had had a spell of being NEET on this basis (Table 1).

(Table 1 near here: Young people in NEET status aged 16-19 in the LSYPE)

\section{Method}

The main research question investigated in this study is: "Does crime in the location influence young people's life chances and if so, how?". In attempting to investigate the research question posed, a key problem must be addressed: a selection bias exists, as the neighbourhood context of the young person is not allocated randomly but rather is chosen by their parents. Hence, it has been difficult in the literature to separate genuine neighbourhood effects on young people's outcomes from the effects of 
specific characteristics of the families who decide to live in a certain neighbourhood (Galster 2008, Hedman and van Ham 2012, Manski 1993, Tienda 1990).

In an attempt to address the selection bias issue, researchers have used experiments to control for family characteristics associated with neighbourhood selection. An example is the "Moving to Opportunity" programme in the United States which involved relocating families from public housing in poor neighbourhoods to other housing in less poor neighbourhoods (Ludwig, Duncan, and Hirschfield 2001, Ludwig et al. 2008). Random experiments allow a better estimate of neighbourhood effects because researchers can control for family characteristics associated with neighbourhood selection and in this way reduce the selection bias problem. Whatever evaluation of the potential advantages of such random experiments may be reached, in practice they are still rare due to practical problems, implementation difficulties and ethical considerations.

In the absence of experimental data in this study, a longitudinal design was selected to investigate the association between neighbourhood deprivation and young people's outcomes. This approach was considered the best alternative to experimental studies as it offers a large number of variables that permit neighbourhood effects to be investigated. To examine the relationship between NEET status and neighbourhood characteristics while controlling for a set of other influences on NEET status, regression models were used. The outcome of interest is binary, and therefore a binary logistic regression model was chosen. This approach analyses the impact of explanatory variables on the probability that the outcome occurred. The outcome variable is coded one for those who were NEET for six months or more at the ages of 18 to 19 and zero for those who were not. The LSYPE study offers a wide range of explanatory variables that could potentially be included in the analysis. Initial selection of variables that could 
be important predictors of entering NEET status was guided by past research (Britton et al. 2011, Chowdry, Crawford, and Goodman 2009). The selection process began by assessing each variable and its association with NEET status individually. Multiple logistic regression models were then estimated separately for each of the four pathways described earlier so as to derive the key indicators for each pathway. Models were then built sequentially adding variables from each pathway in a series of steps as shown in the tables below.

\section{Results}

A sequence of estimated models are reported in Table 2. The first model contains just the quartiles of the crime deprivation measure and no controls. The second model adds controls for the family background of the young person, and the remaining models add further controls for their individual characteristics, for attitudes to/experience of school and for peer groups and anti-social behaviour. In the absence of any controls (Model 1) the coefficients on the three deprivation quartiles were highly significant in relation to the reference category, which was the least deprived quartile. The size of the coefficient for the most deprived quartile decreased as the initial set of controls for family background were added (Model 2) but then remained significant and of roughly the same magnitude as further controls were added in Models 3 through 5.

(Table 2 near here: Results from logistic regression models presented as coefficients)

The core result here then was that there was a significant association (at the $1 \%$ level, $\mathrm{p}<0.001$ ) between the probability of becoming NEET at ages of 18 to 19 and living in a high crime area. The results remained significant even after controlling for a very wide range of other factors which might influence the probability of becoming NEET. There was no compelling evidence of any difference between moderate and low crime areas in the likelihood of becoming NEET at 18 to 19 at Models 2 through 5. In 
Model 5 however, the results indicate that there is a higher probability for young people to become NEET at the ages 18 to 19 if they lived in high Crime areas compared to areas with low Crime Score.

(Table 3 near here: Results from logistic regression models presented as odds ratios)

Table 3 reports the same results in the form of odds ratios, to clarify the size of any effects. In the absence of any controls being in the most deprived quartile of neighbourhoods was associated with a more than double $\left(2.498^{* * *}\right)$ of the odds of being NEET relative to those in the least deprived quartile of neighbourhoods. Including control variables reduced the odds ratio somewhat but even with the full set of controls as shown in the last column of Table 3 the odds of being NEET were approximately 85 per cent greater than those in the least deprived areas. So neighbourhood deprivation - in the form of being in a high Crime area - was associated with a substantial increase in the odds of being NEET.

Table 4 reports estimates from our final model (Model 5) in full so as to bring out clearly the influence of other factors on NEET status. Among family characteristics, for instance, young people in disadvantaged households, such as those on benefits and single parent families, were significantly more likely to become NEET. As for individual characteristics, low educational attainment was significantly associated with an increased probability of being NEET. The estimates suggest that, other things equal, being in the lowest quartile of attainment at Key Stage 2 doubled the odds of subsequently becoming NEET. There was rather little apparent impact of ethnicity on NEET status once other factors were controlled for. Other things equal, the model predicts that those from the Indian ethnic group followed by those from Black African and Bangladeshi origin were less likely to be NEET (relative to the reference group, White). 
Negative attitudes towards, and unfavourable experience of school, were associated with becoming NEET. The specific measures which we used here were playing truant, counting minutes until the end of the lesson, and the young person perceiving themselves not to be good at maths. Finally, variables to reflect peer groups and anti-social behaviour - being excluded from a group of peers at school, and being in contact with police, respectively - were also associated with an increased probability of becoming NEET $(\mathrm{p}<0.01)$.

(Table 4 near here: Results from multiple logistic regression model of becoming NEET. Final model including Crime Score, family, individual, school and peer group characteristics)

Further analysis was carried out as a robustness check by modifying the regression specification. Logistic regression models were run to test for the effect of living in a disadvantaged area on becoming NEET for the whole 40-month period (Sept 2006 to December 2009) for which there is data availability on young people's main activity. The results (see Appendix) are similar to the analysis presented above and confirm the initial hypothesis that living in an area characterised by high crime has negative consequences on young people's educational and employment outcomes.

\section{Discussion and Conclusion}

The aim of this study has been to understand the role of neighbourhood context on young people's transitions through exploring structural and social aspects of neighbourhoods. Structural aspects of neighbourhoods are explained by the economic and social characteristics of the individuals who live there. They are theoretically explored by theories of social organization which refer to low income residents, socially disorganised societies and antisocial behaviour. Structural characteristics have been explored in this study by the individual and parental pathways introduced by the 
“compositional model of neighbourhood effects". In congruence with social organisation theories, the study finds that there is a higher association of disengagement from education and employment for young people whose parents had no educational qualifications, claimed benefits or were single parents. In addition, low educational attainment was a strongly significant covariate in predicting NEET status.

Social characteristics of neighbourhoods refer to social ties and personal networks and are theoretically explained by social isolation theories which point to social networks in disadvantaged areas. Such networks increase the likelihood that young people will be exposed to antisocial behaviour in their peer group. Social characteristics have been tested in this study by the peer group influence and attitudes to schooling pathways. The results suggest that playing truant, feeling bored at school, and having low self-perceived ability at maths were significant predictors of NEET status in the model. Further, peer group factors such as exclusion from a group of friends and the police getting in touch with the young person's parents for their behaviour, increased the odds of becoming NEET.

This study has used quantitative methodology to test whether crime is one characteristic that illuminates the mechanisms which may influence the trajectories of young people in disadvantaged areas. Given that qualitative research has explored the social characteristics of disadvantaged areas (Atkinson and Kintrea 1998, Hastings and Dean 2003, Martin and Watkinson 2003, Wacquant 1993), it is suggested that future research might explore neighbourhood mechanisms using a combination of quantitative and qualitative data (Galster 2008, Lupton 2003, Newman and Massengill 2006, Small and Feldman 2012). Mixed methods would allow researchers to gain insights of how young people and their parents interact in their neighbourhoods as geographic and social spaces. This, would enable the investigation of young people's experiences and 
perceptions, negative role models, isolation from job networks, weakened social institutions and services, and the development of a culture that permits withdrawal from education and employment.

In the exploration of young people's trajectories in disadvantaged areas, the association between crime and young people in NEET status stresses a potential area of concern among policy makers. In the past, policies to tackle NEETs focused on improving educational and work opportunities. However the role of crime in shaping individual outcomes means that successful interventions to improve neighbourhoods will not only increase safety but will also have benefits on other areas such as young people's educational and employment outcomes. It is essential that future interventions should specifically target and engage young people from disadvantaged areas. Intervention programmes should enable and enhance access to the information and resources which are required for young people to reorient their priorities and to take advantage of the opportunities available to realize their potential (Hutchinson, Beck, and Hooley 2016).

\section{Appendix}

\section{Robustness checks for the ages 16-19}

(Table 1 near here: Results from multiple logistic regression model of becoming NEET at the ages 16-19. Final model including Crime Score, family, individual, school and peer group characteristics) 


\section{References}

Aber, JL, M Gephart, J Brooks-Gunn, J Connell, and MB Spencer. 1997.

"Neighborhood, family, and individual processes as they influence child and adolescent outcomes." Neighborhood poverty 1:44-61.

Anderson, Elijah. 2000. Code of the street: Decency, violence, and the moral life of the inner city: WW Norton \& Company.

Atkinson, Rowland, and Keith Kintrea. 1998. Reconnecting excluded communities: The neighbourhood impacts of owner occupation. Edinburgh: Scottish Homes.

Barry, Frank, and James Garbarino. 2001. Handbook of Prevention and Treatment with Children and Adolescents: Intervention in the Real World Context. . Edited by Robert T. Ammerman and Michel Hersen, Children and the Community: University of Texas Press.

Bell, David, and David Blanchflower. 2010. "UK unemployment in the great recession." National Institute Economic Review 214 (1):3-25.

Bell, David, and David Blanchflower. 2011. "Young people and the Great Recession." Oxford Review of Economic Policy 27 (2):241-267.

Britton, Jack, Paul Gregg, Lindsey Macmillan, and Sam Mitchell. 2011. The early bird... preventing young people from becoming a NEET statistic. Department of Economics and CMPO, University of Bristol Report commissioned by Praxis.

Bronfenbrenner, Urie. 1979. The ecology of human development: Experiments by design and nature: Cambridge, MA: Harvard University Press.

Browning, Christopher R., Tama Leventhal, and Jeanne Brooks-Gunn. 2005. "Sexual Initiation in Early Adolescence: The Nexus of Parental and Community Control." American Sociological Review 70 (5):758-778.

Bynner, John, Elsa Ferri, and Peter Shepherd. 1997. Twenty-something in the 1990s: Getting on, getting by, getting nowhere: Ashgate.

Bynner, John, and Samantha Parsons. 2001. "Qualifications, basic skills and accelerating social exclusion." Journal of Education and Work 14 (3):279-291.

Case, Anne C, and Lawrence F Katz. 1991. The company you keep: The effects of family and neighborhood on disadvantaged youths. National Bureau of Economic Research. 
Chowdry, Haroon, Claire Crawford, and Alissa Goodman. 2009. Drivers and barriers to educational success-evidence from the Longitudinal Study of Young People in England. DCSF Research Report 102. London: DCSF

Coleman, James S. 1988. "Social capital in the creation of human capital." American journal of sociology:S95-S120.

Coles, Bob, Christine Godfrey, Antonia Keung, Steven Parrott, and Jonathan Bradshaw. 2010. Estimating the life-time cost of NEET: 16-18 year olds not in Education, Employment or Training. Vol. 15. Audit Commission. University of York

Crane, Jonathan. 1991. "The Epidemic Theory of Ghettos and Neighborhood Effects on Dropping Out and Teenage Childbearing." American Journal of Sociology 96 (5):1226-1259. doi: 10.1086/229654.

Croll, Paul. 2004. "Families, social capital and educational outcomes " British Journal of Educational Studies 52 (4):390-416.

Crowley, Lizzie, and Nye Cominetti. 2014. The geography of youth unemployment: a route map for change. The Work Foundation: University of Lancaster.

Devadason, Ranji. 2006. "Class, ethnicity and individualisation: young adult narratives of transition in two European cities." Journal of Education and Work 19 (2):153-169. doi: 10.1080/13639080600668002.

Dickerson, Andy, and Paul Jones. 2004. Estimating the impact of a minimum wage on the labour market behaviour of 16 and 17 year olds: LPC Commissioned Research.

Elder, Glen H. 1998. "The life course as developmental theory." Child development 69 (1):1-12.

Feng, Zhiqiang, Dawn Everington, and Kevin Ralston. 2015. Consequences, risk factors, and geography of young people not in education, employment or training (NEET). Scottish Government Social Research.

Fenton, Alex. 2013. Small-area measures of income poverty, CASE Paper No 173. London: London School of Economics.

Finlay, Ian, Marion Sheridan, Jane McKay, and Hope Nudzor. 2010. "Young people on the margins: in need of more choices and more chances in twenty-first century Scotland." British Educational Research Journal 36 (5):851-867. doi: 10.1080/01411920903168532. 
Furlong, Andy. 2006. "Not a very NEET solution." Work, employment and society 20 (3):553-569. doi: 10.1177/0950017006067001.

Galster, George C. 2008. "Quantifying the effect of neighbourhood on individuals: Challenges, alternative approaches, and promising directions." Schmollers jahrbuch 128 (1):7-48.

Garbarino, James. 1982. Children and families in the social environment. Transaction Publishers.

Giele, Janet Z, and Glen H Elder. 1998. Methods of life course research: Qualitative and quantitative approaches: Sage.

Gregg, Paul, and Emma Tominey. 2005. "The wage scar from male youth unemployment." Labour Economics 12 (4):487-509. doi: https://doi.org/10.1016/j.labeco.2005.05.004.

Hastings, Annette, and Jo Dean. 2003. "Challenging images: tackling stigma through estate regeneration." Policy \& Politics 31 (2):171-184.

Hedman, Lina, and Maarten van Ham. 2012. "Understanding Neighbourhood Effects: Selection Bias and Residential Mobility." In Neighbourhood Effects Research: New Perspectives, edited by Maarten van Ham, David Manley, Nick Bailey, Ludi Simpson and Duncan Maclennan, 79-99. Dordrecht: Springer Netherlands.

Hutchinson, Jo, Vanessa Beck, and Tristram Hooley. 2016. "Delivering NEET policy packages? A decade of NEET policy in England." Journal of Education and Work 29 (6):707-727.

Jencks, Christopher, and Susan E Mayer. 1990. "The social consequences of growing up in a poor neighborhood." In Inner-city poverty in the United States, 186.

Karyda, Magdalene. 2015. "The effect of crime in the community on becoming not in education, employment or training (NEET) at 18-19 years in England." PhD, UCL

Larsen, Britt Østergaard, Leif Jensen, and Torben Pilegaard Jensen. 2014. "Transitions in secondary education: Exploring effects of social problems." Research in Social Stratification and Mobility 38:32-42. doi: http://dx.doi.org/10.1016/j.rssm.2014.05.001.

Leventhal, Tama, and Jeanne Brooks-Gunn. 2000. "The neighborhoods they live in: the effects of neighborhood residence on child and adolescent outcomes." Psychological bulletin 126 (2):309. 
Ludwig, Jens, Greg J Duncan, and Paul Hirschfield. 2001. "Urban poverty and juvenile crime: Evidence from a randomized housing-mobility experiment." Quarterly Journal of Economics 116 (2):655-680.

Ludwig, Jens, Jeffrey B Liebman, Jeffrey R Kling, Greg J Duncan, Lawrence F Katz, Ronald C Kessler, and Lisa Sanbonmatsu. 2008. "What can we learn about neighborhood effects from the Moving to Opportunity experiment." American Journal of Sociology 114 (1):144-188.

Lupton, Ruth. 2003. "Neighbourhood effects: can we measure them and does it matter?" CASE paper 73, LSE.

MacMillan, Lindsey, Paul Gregg, and Jack Britton. 2012. Youth unemployment: the crisis we cannot afford. London: ACEVO Commission on Youth Unemployment.

Maguire, Sue. 2015. "NEET, unemployed, inactive or unknown - why does it matter?" Educational Research 57 (2):121-132. doi: 10.1080/00131881.2015.1030850.

Maholmes, Valerie, and Rosalind Berkowitz King. 2012. The Oxford handbook of poverty and child development: OUP USA.

Manski, Charles F. 1993. "Identification of Endogenous Social Effects: The Reflection Problem." The Review of Economic Studies 60 (3):531-542. doi: $10.2307 / 2298123$.

Martin, Graham, and Judi Watkinson. 2003. Rebalancing communities: Introducing mixed incomes into existing rented housing estates: Joseph Rowntree Foundation York.

Massey, D. 1994. Space, place and gender Polity Press: Cambridge: Polity Press. McCulloch, Andrew, and Heather E Joshi. 2001. "Neighbourhood and family influences on the cognitive ability of children in the British National Child Development Study." Social science \& medicine 53 (5):579-591.

Mroz, Thomas A, and Timothy H Savage. 2006. "The long-term effects of youth unemployment." Journal of Human Resources 41 (2):259-293.

Murray, Charles A. 1999. The underclass revisited: American Enterprise Institute. Newman, Katherine S, and Rebekah Peeples Massengill. 2006. "The texture of hardship: Qualitative sociology of poverty, 1995-2005." Annual review of sociology 32:423-446. 
Oreopoulos, Philip, and Kjell G Salvanes. 2011. "Priceless: The nonpecuniary benefits of schooling." The journal of economic perspectives 25 (1):159-184.

Raffe, David. 2003. Young people not in education, employment or training: Centre for Educational Sociology, University of Edinburgh Edinburgh.

Reiter, Herwig, and Tabea Schlimbach. 2015. "NEET in disguise? Rival narratives in troubled youth transitions." Educational Research 57 (2):133-150. doi: 10.1080/00131881.2015.1030851.

Rennison, Joanne, Sue Maguire, Sue Middleton, and Karl Ashworth. 2006. Young people not in education, employment or training: evidence from the Education Maintenance Allowance Pilots Database. DfES Research Report 628. London: DfES.

Roberts, Steven. 2011. "Beyond 'NEET' and 'tidy' pathways: considering the 'missing middle' of youth transition studies." Journal of Youth Studies 14 (1):21-39. doi: 10.1080/13676261.2010.489604.

Sampson, Robert J. 2001. "How do communities undergird or undermine human development? Relevant contexts and social mechanisms." In Does it take a village? Community effects on children, adolescents, and families, 3-30. Psychology Press.

Sampson, Robert J, Jeffrey D Morenoff, and Thomas Gannon-Rowley. 2002. "Assessing "neighborhood effects": Social processes and new directions in research." Annual review of sociology 28 (1):443-478.

Sampson, Robert J. 1997. "Collective Regulation of Adolescent Misbehavior." Journal of Adolescent Research 12 (2):227-244. doi: doi:10.1177/0743554897122005.

Shaw, Clifford Robe, and Henry Donald McKay. 1942. Juvenile delinquency and urban areas. University of Chicago Press.

Small, Mario Luis, and Jessica Feldman. 2012. "Ethnographic evidence, heterogeneity, and neighbourhood effects after moving to opportunity." In Neighbourhood effects research: New perspectives, 57-77. Springer.

Small, Mario Luis, and Katherine Newman. 2001. "Urban Poverty after The Truly Disadvantaged: The Rediscovery of the Family, the Neighborhood, and Culture." Annual Review of Sociology 27 (1):23-45. doi: 10.1146/annurev.soc.27.1.23. 
Spielhofer, Thomas. 2009. Increasing participation: understanding young people who do not participate in education or training at 16 and 17. DCSF Research Report 072.

Steinberg, Laurence. 1990. "Autonomy, conflict, and harmony in the family relationship." In At the threshold: The developing adolescent edited by S. S. Feldman \& G. R. Elliott, 255-276. Cambridge, MA: Harvard University Press. Strand, Steve. 2007. Minority ethnic pupils in the Longitudinal Study of Young People in England: Extension report on performance in public examinations at age 16. DCSF Research Report RR-002.

Thompson, Ron, Lisa Russell, and Robin Simmons. 2014. "Space, place and social exclusion: an ethnographic study of young people outside education and employment." Journal of Youth Studies 17 (1):63-78. doi: 10.1080/13676261.2013.793793.

Tienda, Marta. 1990. "Poor people and poor places: deciphering neighborhood effects on poverty outcomes." In Macro-Micro Linkages in Sociology, edited by J. Huber, 204-212. Sage Publications.

Unit, Neighbourhood Renewal. 2004. The English indices of deprivation 2004 (revised). London: Office for the Deputy Prime Minister.

Wacquant, Loïc JD. 1993. "Urban outcasts: stigma and division in the black American ghetto and the French urban periphery." International journal of urban and regional research 17 (3):366-383.

Williamson, Howard 1997. "Status Zer0 youth and the underclass." In Youth, The Underclass and Social Exclusion, edited by Robert MacDonald. London: Routledge.

Wilson, William Julius. 2012. The truly disadvantaged: The inner city, the underclass, and public policy. University of Chicago Press.

Wolf, Alison. 2011. Review of vocational education: the Wolf report. 
Table 1: Young people in NEET status aged 16-19 in the LSYPE.

\begin{tabular}{lcccc} 
Year & Age & $\begin{array}{c}\text { NEET }(1 \\
\text { month or } \\
\text { more })\end{array}$ & $\begin{array}{c}\text { NEET (six } \\
\text { month or } \\
\text { more })\end{array}$ & $\begin{array}{c}\text { Total number } \\
\text { of young } \\
\text { people }\end{array}$ \\
\hline 2006 (Sep-Dec) & 16 & $791(6.77 \%)$ & - & 11,691 \\
2007 (Jan - Dec) & 17 & $1,269(11.79 \%)$ & $618(5.74 \%)$ & 10,762 \\
2008 (Jan - Dec) & 18 & $1,913(19.61 \%)$ & $814(8.34 \%)$ & 9,756 \\
2009 (Jan - Dec) & 19 & $1,611(18.92 \%)$ & $1,121(13.17 \%)$ & 8,513 \\
$2008-2009(24$ months) & $18-19$ & $2,268(25.52 \%)$ & $1,351(15.20 \%)$ & 8,887 \\
$2006-2009$ (40 months) & $16-19$ & $2,436(28.73 \%)$ & $1,602(18.89 \%)$ & 8,480 \\
\hline
\end{tabular}

Table 2: Results from logistic regression models presented as coefficients.

\begin{tabular}{|c|c|c|c|c|c|}
\hline & Model 1 & Model 2 & Model 3 & Model 4 & Model 5 \\
\hline $\begin{array}{l}\text { Index of area } \\
\text { deprivation: Crime } \\
\text { Score }\end{array}$ & $\begin{array}{l}\text { Coeff } \\
\text { (std err) }\end{array}$ & $\begin{array}{l}\text { Coeff } \\
\text { (std err) }\end{array}$ & $\begin{array}{l}\text { Coeff } \\
\text { (std err) }\end{array}$ & $\begin{array}{l}\text { Coeff } \\
\text { (std err) }\end{array}$ & $\begin{array}{l}\text { Coeff } \\
\text { (std err) }\end{array}$ \\
\hline Second quartile & $\begin{array}{l}0.368 * * * \\
0.1\end{array}$ & $\begin{array}{l}0.308 * * \\
0.11\end{array}$ & $\begin{array}{l}0.313^{* *} \\
0.111\end{array}$ & $\begin{array}{l}0.261 * \\
0.117\end{array}$ & $\begin{array}{l}0.217 \\
0.121\end{array}$ \\
\hline Third quartile & $\begin{array}{l}0.552 * * * \\
0.101\end{array}$ & $\begin{array}{l}0.378 * * \\
0.114\end{array}$ & $\begin{array}{l}0.381^{* *} \\
0.115\end{array}$ & $\begin{array}{l}0.417 * * \\
0.121\end{array}$ & $\begin{array}{l}0.365^{* *} \\
0.125\end{array}$ \\
\hline $\begin{array}{l}\text { Fourth quartile (most } \\
\text { deprived) }\end{array}$ & $\begin{array}{l}0.915^{* * *} \\
0.1\end{array}$ & $\begin{array}{l}0.702 * * * \\
0.115\end{array}$ & $\begin{array}{l}0.691 * * * \\
0.117\end{array}$ & $\begin{array}{l}0.718 * * * \\
0.124\end{array}$ & $\begin{array}{l}0.613^{* * * *} \\
0.13\end{array}$ \\
\hline \multicolumn{6}{|l|}{ Controls for: } \\
\hline $\begin{array}{l}\text { Family background, } \\
\text { practices, aspirations }\end{array}$ & No & Yes & Yes & Yes & Yes \\
\hline $\begin{array}{l}\text { Individual } \\
\text { characteristics }\end{array}$ & No & No & Yes & Yes & Yes \\
\hline $\begin{array}{l}\text { Attitudes to, and } \\
\text { experience of school }\end{array}$ & No & No & No & Yes & Yes \\
\hline $\begin{array}{l}\text { Peer groups and anti- } \\
\text { social behaviour }\end{array}$ & No & No & No & No & Yes \\
\hline \multicolumn{6}{|c|}{$* p<0.05, * *<0.01, * * *<0.001$} \\
\hline $\mathrm{N}$ (weighted count) & 8,347 & 7,204 & 7,198 & 6,304 & 5,883 \\
\hline Wald Chi2 & 85.85 & 226.38 & 331.49 & 312.47 & 297.68 \\
\hline Pseudo R2 & 0.0169 & 0.0538 & 0.077 & 0.0852 & 0.0873 \\
\hline
\end{tabular}


Table 3: Results from logistic regression models presented as odds ratios.

Index of Area

Deprivation: Model 1 Model 2 Model 3 Model 4 Model 5

Crime Score

\begin{tabular}{|c|c|c|c|c|c|}
\hline $\begin{array}{l}\text { Second } \\
\text { quartile }\end{array}$ & $1.444 * * *$ & $1.361 * *$ & $1.367 * *$ & $1.298 *$ & 1.242 \\
\hline Third quartile & $1.738^{* * *}$ & $1.459 * *$ & $1.464 * *$ & $1.518^{* *}$ & $1.441 * *$ \\
\hline $\begin{array}{l}\text { Fourth quartile } \\
\text { (most } \\
\text { deprived) }\end{array}$ & $2.498 * * *$ & $2.017 * * *$ & $1.996^{* * *}$ & $2.050 * * *$ & $1.847 * * *$ \\
\hline Controls for: & & & & & \\
\hline $\begin{array}{l}\text { Family } \\
\text { background, } \\
\text { practices, } \\
\text { aspirations }\end{array}$ & No & Yes & Yes & Yes & Yes \\
\hline $\begin{array}{l}\text { Individual } \\
\text { characteristics }\end{array}$ & No & No & Yes & Yes & Yes \\
\hline $\begin{array}{l}\text { Attitudes to, } \\
\text { and experience } \\
\text { of school }\end{array}$ & No & No & No & Yes & Yes \\
\hline $\begin{array}{l}\text { Peer groups } \\
\text { and anti-social } \\
\text { behaviour }\end{array}$ & No & No & No & No & Yes \\
\hline
\end{tabular}


Table 4: Results from multiple logistic regression model of becoming NEET. Final model including Crime Score, family, individual, school and peer group characteristics.

\begin{tabular}{|l|c|c|c|c|}
\hline & Coeff. & Std. Err. & Sign. & Odds Ratio \\
\hline Crime Score 2nd quartile & 0.217 & 0.121 & 0.074 & 1.242 \\
\hline Crime Score 3rd quartile & 0.365 & 0.125 & 0.003 & 1.441 \\
\hline $\begin{array}{l}\text { Crime Score 4th quartile (most } \\
\text { deprived) }\end{array}$ & 0.613 & 0.13 & 0 & 1.847 \\
\hline $\begin{array}{l}\text { Highest qualification of Main Parent: } \\
\text { No qualification }\end{array}$ & 0.373 & 0.123 & 0.002 & 1.453 \\
\hline Benefit claimants & 0.428 & 0.101 & 0 & 1.534 \\
\hline Mother birth age under 20 & 0.213 & 0.159 & 0.182 & 1.238 \\
\hline Single parent family & -0.194 & 0.113 & 0.087 & 0.823 \\
\hline Parental monitoring: Sometimes & 0.204 & 0.297 & 0.493 & 1.226 \\
\hline Parental aspirations: Full time education & -0.179 & 0.115 & 0.119 & 0.835 \\
\hline KS2 1st quartile (low attainment) & 0.712 & 0.106 & 0 & 2.039 \\
\hline Ethnic group (reference: White) & & & & \\
\hline Mixed Ethnicity & -0.115 & 0.217 & 0.596 & 0.891 \\
\hline Indian & -1.153 & 0.226 & 0 & 0.315 \\
\hline Pakistani & -0.104 & 0.231 & 0.652 & 0.9 \\
\hline Bangladeshi & -0.883 & 0.343 & 0.01 & 0.413 \\
\hline Black Caribbean & -0.183 & 0.272 & 0.501 & 0.832 \\
\hline Black African & -1.288 & 0.461 & 0.005 & 0.275 \\
\hline Other Ethnicity & -0.364 & 0.397 & 0.358 & 0.694 \\
\hline Young person played truant & 0.541 & 0.119 & 0 & 1.719 \\
\hline In a lesson counts minutes till it ends & 0.261 & 0.12 & 0.029 & 1.299 \\
\hline $\begin{array}{l}\text { Young person feels not very good at } \\
\text { maths }\end{array}$ & 0.566 & 0.268 & 0.035 & 1.762 \\
\hline $\begin{array}{l}\text { Police got in touch with main parent for } \\
\text { young person's behaviour }\end{array}$ & 0.507 & 0.172 & 0.003 & 1.66 \\
\hline $\begin{array}{l}\text { Young person was excluded from a } \\
\text { group of friends }\end{array}$ & 0.304 & 0.112 & 0.007 & 1.356 \\
\hline N (weighted count): 5,883 & & & & \\
\hline Wald Chi2: 297.68 & & & & \\
\hline Pseudo R2: 0.0873 & & & \\
\hline
\end{tabular}


Appendix

Table 1: Results from multiple logistic regression model of becoming NEET at the ages 16-19. Final model including Crime Score, family, individual, school and peer group characteristics.

\begin{tabular}{|l|c|c|c|c|}
\hline & Coeff. & Std. Err. & Sig. & Odds Ratio \\
\hline Crime Score 2nd quartile & 0.196 & 0.092 & 0.033 & 1.217 \\
\hline Crime Score 3rd quartile & 0.289 & 0.097 & 0.003 & 1.335 \\
\hline Crime Score 4th quartile & 0.522 & 0.104 & 0 & 1.685 \\
\hline $\begin{array}{l}\text { Highest qualification of Main Parent: } \\
\text { No qualification }\end{array}$ & 0.49 & 0.1 & 0 & 1.633 \\
\hline Benefit claimants & 0.372 & 0.079 & 0 & 1.451 \\
\hline Mother birth age under 20 & 0.141 & 0.128 & 0.271 & 1.152 \\
\hline Single parent family & -0.189 & 0.093 & 0.042 & 0.826 \\
\hline Parental monitoring: Sometimes & 0.537 & 0.263 & 0.042 & 1.711 \\
\hline Parental aspirations: Full time education & -0.422 & 0.092 & 0 & 0.655 \\
\hline KS2 1 st quartile (low attainment) & 0.665 & 0.091 & 0 & 1.945 \\
\hline Ethnic group (reference: White) & & & & \\
\hline Mixed Ethnicity & -0.108 & 0.178 & 0.54 & 0.896 \\
\hline Indian & -0.688 & 0.175 & 0 & 0.502 \\
\hline Pakistani & -0.372 & 0.199 & 0.062 & 0.689 \\
\hline Bangladeshi & -0.79 & 0.272 & 0.004 & 0.453 \\
\hline Black Caribbean & -0.222 & 0.232 & 0.339 & 0.8 \\
\hline Black African & -1.043 & 0.28 & 0 & 0.352 \\
\hline Other Ethnicity & -0.497 & 0.322 & 0.123 & 0.607 \\
\hline Young person played truant & 0.58 & 0.104 & 0 & 0.178 \\
\hline In a lesson counts minutes till it ends & 0.383 & 0.1 & 0 & 1.467 \\
\hline $\begin{array}{l}\text { Young person feels not very good at } \\
\text { maths }\end{array}$ & $0.323 *$ & 0.248 & 0.193 & 1.381 \\
\hline $\begin{array}{l}\text { Police got in touch with main parent for } \\
\text { young person's behaviour }\end{array}$ & 0.686 & 0.155 & 0 & 1.986 \\
\hline $\begin{array}{l}\text { Young person was excluded from a } \\
\text { group of friends }\end{array}$ & 0.312 & 0.089 & 0 & 1.367 \\
\hline N (weighted count): 5,843 & & & & \\
\hline Wald Chi2: 396.85 & & & & \\
\hline Pseudo R2: 0.0915 & & & & \\
\hline
\end{tabular}

